\title{
Clinical Trial Safety Status Report Documentation
}

National Cancer Institute

\section{Source}

National Cancer Institute. Clinical Trial Safety Status Report Documentation. NCI

Thesaurus. Code C115631.

Records detailing the standing of the clinical trial as it relates to safety concerns. 